\title{
University Education System as a Research Environment for the Training of PhD Students
}

\author{
Boris Manov \\ ORCID: oooo-0oo2-4956-3598 • ResearcherID: F-4196-2014 \\ Valentina Milenkova \\ ORCID: oooo-0oo2-7592-1475 • ResearcherID: F-2581-2014 \\ South-West University “Neofit Rilski”, Blagoevgrad \\ Received 22 October 2017 • Revised 20 November 2017 • Accepted 22 November 2017

\section{Abstract} \\ The present article aims to analyze some aspects of Ph.D. training as a specific basis for \\ intellectual establishment and research support focusing on the following issues: What are the \\ characteristics of Ph.D. students' integration to research activities? How young people evaluate \\ various research processes? What is the department support as an institutional unit to doctoral \\ students? What is the role of the family in the carrying out of Ph.D. process? The analysis focuses \\ on the support that students from the Faculty of Philosophy, South-West University (SWU) \\ receive for their research activity from their families and the institution they graduate. The paper \\ is based on results obtained through quantitative as well as qualitative methods in the course of \\ research projects carried out in 2013, 2015, and 2017 at SWU. The main methods of obtaining \\ information are focus groups and survey conducted with graduate students in the Faculty of \\ Philosophy, SWU. The basic conclusion of the study is that Ph.D. student's research activity is a \\ prerequisite for their future professional identity. The establishment of research skills is directly \\ related to the support that doctoral students receive from the department, by the assistance of \\ their supervisor and other professors who encourage creative activity, applying individual \\ approach and seek active communication based on person-centered pedagogy. Meanwhile, the \\ psychological support of the family is a no less important part of the received support, stimulating \\ the construction of individuality in the process of socialization of young researchers.
}

Keywords: Ph.D research activity, university, quality of support, departmental environment.

\section{Introduction}

In the present times serious changes are taking place in all the fields of politics, economics, culture, education, international relations; deep and dynamic situations of restructuring and globalisation are developing (Beck, 1992; 1999; Nedyalkova, et al., 2005). Globalisation is putting forward the question of the place of science and the growing importance of research work and skills (Giddens, 2009), of the way they become a part of a person's professionalism and his/her placing in society. In that context university education is attaining a central role as it provides key skills to students and it is focused on obtaining knowledge and qualification which are specialized and science centred.

(C) Authors. Terms and conditions of Creative Commons Attribution 4.0 International (CC BY 4.0) apply. Correspondence: Valentina Milenkova, Ivan Mihailov 66, 2700 Blagoevgrad, Bulgaria. E-mail: vmilenkova@gmail.com. 
The university is the institution that provides unity of training and research and in this sense focuses its efforts on the formation of Ph.D. students such as social actors who ensure the continuity of scientific work and research activities. The issues related to doctoral training are particularly important and current today. They include the quality of doctoral studies, the qualifications of the supervisors, the skills of Ph.D. students, the development of teamwork and various forms of collaboration, the enhancement of publishing activities and the creation of research networks of Ph.D. students from different national and European universities. All this variety of research and training activities shows the necessity of symbiosis in theoretical, practical and methodological level in understanding the status of Ph.D. students and the process of their formation as future scientists.

\subsection{Objectives}

The present article aims at analyzing several important aspects of rationalizing university education as an environment of intellectual and research transmission putting an accent on the following questions:

work?

- Which are the characteristic features of the initiation of Ph.D. students to research

- What qualities research activity develops?

- How the trained Ph.D. students behave towards different research activities?

- What is the attitude of colleagues and the Department environment related to doctoral training and formation as researchers?

This article is an analysis of the Ph.D. students and their point of view on the current inclusion in different research activities.

\section{Materials and method}

The analysis is based in empirical plan on several sociological surveys, used quantitative and qualitative methods, and covers the period 2013 - 2017.

- The survey "Integration of social- psychological sciences in a globalized world" conducted in 2013 in South-West University (SWU) with team leader prof. Valentina Milenkova. Two methods were used: structured interviews and focus groups. The sample was unrepresentative and included 290 students from various faculties of the university; the sample was made under an experimental design scheme. The other method used was a focus group. There were three focus groups carried out with students and Ph.D. students from Sociology, Psychology and Political Science specialties of SWU.

- A survey "Cultural universals in academic milieu" was carried out in 2015 at SWU with students and Ph.D. students from Social study specialties: Sociology, Political Sciences, and Psychology; there were conducted 5 focus groups. Team leader of the project was prof. Valentina Milenkova.

- A survey in 2017 carried out under the project "The Role of Ph.D. students in modern research process: towards creating highly qualified and proactive staff" in the Faculty of Philosophy at the South-West University with team leader prof. Boris Manov. The study aimed at showing the place of Ph.D. students in the contemporary research process, as well as the improvement and support of their academic work by their thesis supervisor, department, and the family. In the process of the survey $51 \mathrm{Ph}$.D. students 
from the Faculty of Philosophy were questioned anonymously and they were from the majors Psychology, Sociology, Political Science, and Philosophy. The age range was from 24 to 66 years of age. The number of women was 36, and men were 15, which raises the problem of feminization of $\mathrm{Ph}$.D. studies as a degree in the educational and academic training of researchers.

Apart from Ph.D. students, 130 B.A. and M.A. students from all majors of the Faculty of Philosophy were also questioned. B.A. students were 53, and M.A. students were 77 . The research team added the opinions shared by B.A. and M.A. students to the information obtained about Ph.D. students because it was important to study the readiness of B.A. and M.A. students form the teaching programs of the faculty to engage in research activities; whether they had been involved in such activities; do they wish to continue their education in a Ph.D. program; do they receive support from their milieu - colleagues, friends, and family.

The main methods of information gathering were focus groups and survey conducted with graduate students, bachelor and master students in the Faculty of Philosophy, SWU.

\section{Results}

University education is connected with teaching knowledge, qualification and competence, creating a base for the successful realisation of individuals. Higher education corresponds to personal needs for deep knowledge about humans, nature and society, which form the ability of orientation in the world, of the identifying of a personal place within social structures, of the inclusion in social relations. Higher education is important in social plan, because it is connected:

- With acquiring of skills for life in a community, expressed by creation of attitudes and readiness of the individual to communicate and cohabit with his/her coevals, in order to turn into an active participant in the life of the education institutions, to assimilate abilities, shaping his/her practical activities and orientation. Team work as well as "life in community" (Jackson, 1968) is ability, meaning the necessity to confirm to the others, to respect them and even to renounce your own desires, to make compromise with your moods, which is formed within the organisational surroundings of the educational institutions since their earliest forms (Durkheim, 1934; 1956).

- University education is connected with learning knowledge, qualifications and competences, building the cultural and the intellectual mainstay of society. Thus the connection between dominating demands and their mapping through training and education of individuals is supported. University introduces actors in a world of publicly developed meanings whenever the circumstance of a possibility that in certain cases their relative character can manifest itself.

In accordance with its basic activities: training and education, the higher education system is aimed at shaping of definite personal qualities and that might be conscious or not, purposefully or not sought by various agents included into running interactions. But the formation of social consciousness through the training process is not always evident, meaning that the educational system acquires also one hidden function, which is revealed through the interdependence between personal formation and the structure of power realities and relations. That is, higher education, while performing its specific activities concerning the educational process, at the same time realizes its social function of preservation and support of the existing social structure and relations.

Universities socialize through knowledge they teach, by specific rules and values they legitimize, by contacts and sub-cultures they develop and draw individuals into different relations; they socialize also through the basic agents of their influence - professors and lecturers. All those 
sides of the socialization impacts accumulate definite experience in themselves and they become bearers of particular purpose and engagement devoted to shape in accordance to social pattern which determines them. University education should present a unity of training and research and it is necessary for the research process to be realized through student's participation.

That is important, because the inclusion of Ph.D. students into research activities:

(a) Increases the acquired qualification and their professional skills;

(b) Gets students near to laboratories and to the processes of constructing knowledge;

(c) Contributes to acquiring competences through their inclusion into diverse activities ("learning by doing");

(d) Creates attitude towards learning and adoption of new skills and new knowledge.

Through research work:

- doctoral students become more active and interested in training;

- they apply in practice the matter for instruction at lectures and exercises;

- they learn new things and turn into a corrective of professors' work, because they pose questions as well as they ask for additional specifications.

Another important consequence of the participation of doctoral students in research activities is the promotion of their motivation to continue their studies in order to defend their $\mathrm{Ph} . \mathrm{D}$. thesis, as well as to continue their academic and research activities in the future.

An important moment in the research is the selection of topic of the Ph.D. thesis. The topic is of a significant importance because it assures that the research potential of the scholar is developed through it. All Ph.D. students who participated in the survey in the Faculty of Philosophy in 2017 confirmed that the topic of their theses and their academic interests coincide. Also a half of the Ph.D. students shared that their Ph.D. thesis is a continuation of their Master's thesis. This means that there exist succession and continuity in the research work undertaken. This is a prerequisite for deepening the interests in the respective research area but it also means that there is a process of discussing and consideration of the views and plans of the Ph.D. students with respect to support and co-operation from the staff within the separate departments in the Faculty of Philosophy.

Research work in itself is significant, because it aims at complex personal development as from the point of view of obtaining specific skills and competence, as well as concerning qualities necessary for the construction of general attitude towards knowledge. Here are some of the qualities, promoted by research activity:

- Criticism and self-reflection;

- Openness to changes;

- Aptitude towards perfection;

- Ambition and creative approach;

- Higher professionalism;

- Drive towards increasing of qualification.

How do Ph.D. students describe their inclusion into research activities or what are the specific meaningful associations through their view, when they speak about their participation in research work? Shared opinions at the focus groups within the university surveys carried out in 2013 and 2015 were used. 
Respondents pointed at:

- Inclusion in research projects;

- Participation in conferences and round tables;

- Writing articles on different topics;

- Elaboration of creative presentations.

It can be noticed that for Ph.D. students actual participation in research activity was associated mainly with activities bearing in themselves the store of a specialized scientific activity, understood as part of professional occupation with science. At the same time, however, we can add that along with that conception, shared among doctoral students, one has to bear in mind that their incorporation to research work takes place through routine and everyday training practices at classrooms and auditoriums as well, which is connected with:

- assigning specific tasks at lectures, seminars and exercises, literature studies on definite topic, elaboration of papers, making presentations, writing essays, preparation for Ph.D. students' exams.

At every one of the indicated activities, implemented within the framework of training and assigned to doctoral students by their professors a specific research effort, connected with theoretical and exploratory work, with coordination of the team and distribution of the engagements of every one of the members, making of generalisations and presenting the results from theoretical and/or practical work are presumed. Those are all the important everyday efforts, which are necessary, but in fact doctoral students perceive them mainly as training and not as research activity. That is why it is important to accentuate on the fact that the participation of $\mathrm{Ph}$.D. students in research work is connected with the quality of education, the preparation of lecturers themselves, their research engagements, their participation in different scientific nets, with lecturers' and students' readiness to work together.

\subsection{Group environment}

One of the important topics studied during the survey of 2017 was connected to the support received by the Ph.D. students from their milieu - colleagues, family, and friends. In this discourse a special attention is paid to social capital.

The basic idea of social capital is that social contacts and nets have their value and influence individuals' and groups' achievements. As a concept social capital has a long history, connected with different accents and interpretations from its contribution to solidarity and democracy to its importance for the community as a factor to the creation of confidence and the individual free choice (Ferragina, 2012). That is one of the reasons for social capital to generate such a vivid interest in an academic context ${ }^{1}$. Bourdieu (1985) introduced and developed the concept, in the context of "forms of capital" showing how social capital creates and reproduces inequalities, based on directly and indirectly use of public contacts to provide individuals with access to power positions (Portes, 1998).

Contemporary consideration of social capital enforces a debate on the relation between confidence, solidarity and social development, making a synthesis of the values of communal and individual approaches, set in the "rational choice theory". Social capital is generated collectively thanks to the presence of communities and social nets, but individuals and groups are those who use it. Individuals can exploit social capital of their contacts and connections

1 J. Dewey first used the term in 1899 in his book The School and Society (John Dewey) without giving him a definition. 
in order to fulfill their own tasks. In that sense analysis put an accent on dichotomous approach: "communality" vs. "individualism" (Ferragina, 2012).

Social capital is built on the basis of trust which is a relation between social actors. According to Coleman, social capital is not a personal possession but a collective good which is formed due to social relations in the group (Coleman, 1988). Trust between members of the group has a key role. Trust creates security of the expectations for the behavior of the group's members, for fulfilling of the commitments undertaken, for honesty, loyalty, empathy. Thus interpersonal trust also becomes a means of reducing risk and uncertainty which come out of complex and unexpected circumstances external for the group. A significant part of the milieu is the family.

The family has a strong impact on dispositions towards life, future, self-image, work. It creates a specific environment and the total set of conditions related to understanding and care; it is a specific social capital that is inherited in the course of interaction between actors (Coleman, 1988).

Social capital in the family is the relations between all family members but mostly between parents and children. When the human capital (comprising education, skills, and knowledge) possessed by the parents is not complemented by social capital embodied in parentchild relations, the full family socialization is damaged (Coleman 1988).

The family and the parental style of communication have a decisive impact on the relationships that are built within the family and on the personal self-esteem; the latter depends on the degree of autonomy given to the individual and the support it receives from the family. Conversely, the more this style is marked by control, restrictions, poor communication, lack of encouragement for adaptation, the lower self-esteem. Upbringing is not a leveling but a differentiating process and a child from a well-to-do family has better chances for development and mobility than its poorer coevals (Sherman, 1996: 12). In the family an individual assimilates those assessments, definitions, and dispositions towards the world, those forms and styles of thought, which define the central orientations and statuses. In this way are legitimated the ways of connecting to the world, knowledge, ways of speaking (Bernstein 1958; Bernstein, 1975).

Family capital is connected with creating traditions and a life style, linguistic maturity and predispositions, complemented by the dimensions of family cohesion (a style of upbringing style and family relationships); family support becomes an important prerequisite for the formation of a positive attitude to social relations and self-esteem, to confidence and communications. That is why children with a damaged family socialization - including violence at home, lack of supportive environment and relationships - display greater liability.

Family strength defines power of society, its vitality and sufficiency of every person. In connection with this it is important to emphasize that attitude towards research work of doctoral students is something which is constructed and family plays its role in this process, important are individual inclinations and natural abilities as well. All Ph.D. students in the surveys of 2013, 2015 and 2017 declare that they have full support from their families which itself turns into an important element of the ongoing work on the Ph.D. thesis connected to the co-operation of the family in an emotional, social, and economic plan directed to the future development of the Ph.D. students.

The attitudes of colleagues and the overall milieu, in which Ph.D. students' training and formation as researchers take place, is significant for the complete work of Ph.D. students. In this context a special role is played by the thesis supervisor who is the direct tutor and advisor of the Ph.D. student, with whom all basic ideas of the Ph.D. thesis are being discussed, and who follows the progress of the research work. 91.5\% of the surveyed Ph.D. students in 2017 have stated that they receive full support from their thesis supervisor. 
Regarding support from the department, 91.5\% expressed the opinion that they receive support from the department in which their Ph.D. training takes place.

In this sense we can summarize that Ph.D. students at the Faculty of Philosophy of the South-West University in the current moment have the support, co-operation for work and achieving their goals. This support comes from both the family and their colleagues and the educational institution itself as an intellectual milieu and possibilities for research work.

\subsection{Bachelor and Master students about academic work}

In the survey undertaken in 2017 an important moment was the rethinking of the problem of the relation of students (who are not Ph.D. students) to science and research work, as well as their possibilities to continue their training in Ph.D. programs.

Bachelor and Master students (130) from all majors of the Faculty of Philosophy (Psychology, Sociology, Philosophy, and Political Science) were surveyed.

Answering the question: "if they have interest in academic work", more than half of the surveyed Bachelor students state firmly that they would not deal with academic work.

From the Master students from the majors mentioned in the survey almost $65.0 \%$ share that they express interest in academic work. We should especially emphasize that all Master students in Philosophy respond positively. Among Master students in Sociology the greater part (more than 80\%) responds positively. A similar distribution we may find among students in Psychology.

To the question whether they would apply for a Ph.D. program the greater part of the Master students from the Faculty of Philosophy respond "Yes" - 58.4\%. In addition, asked whether they have plans to develop further their Master thesis into a Ph.D. thesis, almost 2/3 (68.8\%) from the Master students surveyed respond positively.

All quoted results are indicative for the attitudes of young people studying in the Social Sciences and Humanities in the faculty, which are that the greater part of students have positive attitude to research and more than the half of the students from both Bachelor and Master programs are inclined to continue their academic activities on a higher structural level. In this connection it is important to reveal the attitude to science in general of all the studied persons (Ph.D., Master and Bachelor students) express their positive attitude to science and research.

In addition it is interesting to follow: What does attract students in research activity taking place in university environment? ${ }^{2}$ First of all that is team-work i.e. "the possibility to discuss different things with the other young people during classes", "the appearance in front of the other colleagues", "field work". It was observed that the majority of students finds attractive the social aspects of research work, namely possibilities for discussions, for establishing of contacts, so that sociability might be considered one of the motivations for including students in different research activities.

In connection to the formation of research attitudes with students the relation education - creative attitude has to be taken into consideration too.

Students participating in the research inquiry carried out in 2013, declared that: "Education has to develop creative attitudes": 86.0\% of the respondents expressed agreement with that statement: 1 - fully agree 61.5\%; 2 - agree: 24.5\%; 3 - neither agree, nor disagree: $11.5 \%$; 4 - disagree: 1.5\%; 5 - fully disagree: o\%; 6 - don't know 1\% (Graph 1).

\footnotetext{
${ }^{2}$ The results are from focus groups carried out in projects under 2013 and 2015.
} 
Graph 1. Education must develop creative attitudes

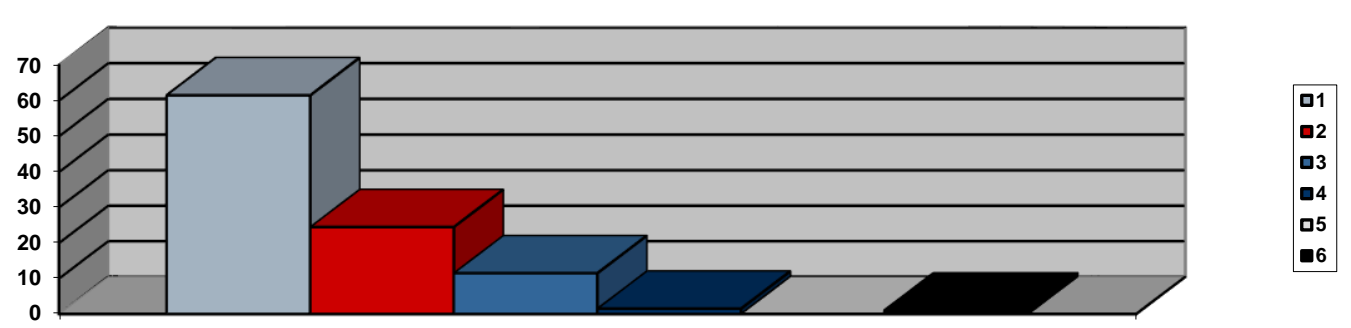

Besides, according to students, education is important for a success in life nowadays in our country (Table 1 and Graph 2).

Table 1. How important is education for success in life nowadays

\begin{tabular}{|c|c|c|c|c|c|}
\hline $\begin{array}{c}\text { Extremely } \\
\text { important } \\
(1)\end{array}$ & $\begin{array}{c}\text { Very } \\
\text { important } \\
(2)\end{array}$ & $\begin{array}{c}\text { Important } \\
(3)\end{array}$ & $\begin{array}{c}\text { Not quite } \\
\text { important } \\
(4)\end{array}$ & $\begin{array}{c}\text { Absolutely } \\
\text { non-important } \\
(5)\end{array}$ & $\begin{array}{c}\text { Don't } \\
\text { know } \\
(6)\end{array}$ \\
\hline 39.5 & 31.5 & 17.5 & 7.5 & 1.5 & 2.5 \\
\hline
\end{tabular}

Graph 2. How important is education for success in life nowadays

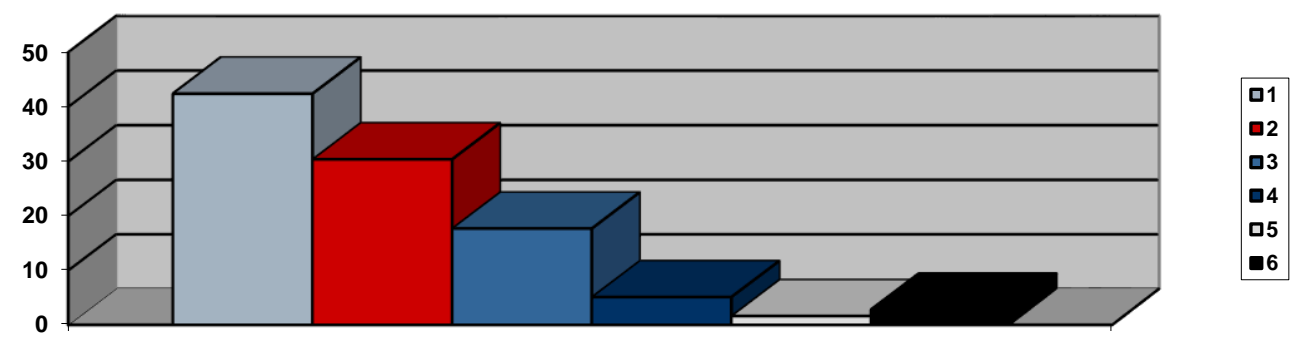

It can be noticed that $88.5 \%$ of respondents have indicted education as an important condition ("extremely important", "very important", "and important") for individual mobility. All that comes in support of the thesis that education is not only a value in itself; it is actually mapped on educational aspirations and strategies of the Bulgarians. Bringing out of education as a mobility factor shows the realization of its prestige and significance as a stimulus for prosperity as education is not a value in itself, but it is important in view of realization in society, taking high statuses and reaching welfare.

\subsection{Estimation of training}

Students did not estimate highly the state of the educational system nowadays. During the inquiry (in 2013) to the question: "What is the state of our educational system?" respondents answered by estimation through a ten-degree scale from oo - "very bad" to 10 - "very good"; responses were as follows (Table 2). 
Table 2. Estimation of the state of education

\begin{tabular}{|c|c|c|c|c|c|c|c|c|c|c|c|c|}
\hline & 00 & 01 & 02 & 03 & 04 & 05 & 06 & 07 & 08 & 09 & 10 & $\begin{array}{c}\text { Don't } \\
\text { know }\end{array}$ \\
\hline $\begin{array}{c}\text { General } \\
\text { estimation }\end{array}$ & 7.8 & 8.7 & 9.3 & 12.9 & 10.5 & 19.5 & 7.4 & 5.7 & 2.6 & 1.6 & 1.5 & 12.5 \\
\hline
\end{tabular}

One could observe from the data that for the general estimation of education in this country basic answers were accumulated in the first half of the scale, showing rather a negative estimation. The reasons for that might be sought out in the absence of overall vision on the reforms going on in Bulgarian education, the lack of continuity between the different teams at the education ministry, leading to disorganisation and to piece-work. From their part that presumes imposition of double standards and net of relations. All that reflects on the institutional surroundings, on the specific situations, connected with difficult realization of the young people, with decline the quality of education and training, with discrepancy of marks and the actual knowledge, with mismatch between knowledge, skills and realization. These are serious problems of the educational system. On the other hand, the important question is: what exactly personal qualities Bulgarian education is forming and it has to form?

\section{Discussion and conclusions}

One of the substantial conclusions of that article is that participation of Ph.D.students in research activity is a prerequisite of achievement of different goals of cognitive and social character, connected with the inclusion of young people in specific nets and structures within the framework of the educational institutions, allowing for displaying of their qualities, attaining qualification and competence, important in personal and in professional plan as well and contributing to their performance. In this context one can conclude that in order to get skills for research, one person has to be connected with another, because those others are exactly the main source of creation of preconditions for the involvement activities. That is why the teams of Ph.D. students enter on the base of interests they share and activities they execute are greatly important. In the long run, research skills and habits acquired through university training, become a substantial characteristic feature of the personal potential and its perfection and those are different sides of the acquisition of social experience and individual significance. It is important to emphasize that the formation of skills for a Ph.D. program is a long lasting process connected to a great extent to the educational institution itself and to the environment which it creates.

Challenges to university education in view of providing research skills to young people are connected with:

- Curricula and study programmes, which have to stimulate more creativity and individual approach, and to correspond to person-centred pedagogy.

- Curricula have to show higher mobility and to include more free-chosen disciplines.

- The opening of universities towards older generations, which might turn the universities into real "life-long learning institutions". It is necessary in connection with that distance training forms to be developed further on.

- The activation of project work at universities level as well as an accent on assigning of different creative tasks to students in the process of training.

Young people do not always express readiness for inclusion in a creative work. Quite often they are inert and non-interested, passive. At the same time they need expression and research work attracts them by: team-work, creativity, performance in front of others - that exactly 
has to stand in the vase of the university approach to youth. However as a whole the inclusion of students in research work depends on the quality of education, on preparedness and the activity of lecturers. In that sense the inclusion of students in research activities is an important element of personal development and realization under the conditions of globalisation. It depends on the specific structure, organisation and purposefulness, based on running models of training and education, the participation of young people in research activities is a prerequisite for their individual prosperity and at the same time it is an indicator of the development of university education and its perspectives.

Ph.D. programs in the Bulgarian conditions are an important factor for the formation of academic staff. They are a period of several years during which Ph.D. students develop their research skills connected to analyticism, creative thinking, sharing ideas, discussions, conducting empirical work. It is namely this period which is important for the future research work and a more active and responsible attitude is needed in an institutional plan to the development of Ph.D. students because the future of science depends on their qualities and responsibilities.

\section{References}

Beck, U. (1999). What is globalization? Cambridge: Polity Press.

Beck, U. (1992). Risk society: Towards a new modernity. London: Sage.

Bernstein, B. (1975). Class, codes and control. London: Routledge \& Kegan Paul.

Bernstein, B. (1958). Some sociological determinants of perception. British Journal of Sociology, 9, 159174 .

Bourdieu, P. (1985). The forms of capital. In J. G. Richardson (Ed.), Handbook of Theory and Research for the Sociology of Education (pp. 241-258). New York: Greenwood.

Coleman, J.S. (1988). Social capital in the creation of human capital. American Journal of Sociology, 94, 95-121.

Dewey, J. (1899). The school and the society. Supplemented by a Statement of the University Elementary School 1907. Chicago: Chicago University Press.

Durkheim, E. (1934). L'éducation morale (Cours dispensé en 1902-1903 à la Sorbonne). Paris: Librairie Félix Alcan.

Durkheim, E.(1956). Education and sociology. New York: Free Press.

Ferragina, E. (2012). Social capital in Europe: A comparative regional analysis. Cheltenham: Edward Elgar.

Giddens, A. (2009). Sociology (6th edition). Polity Press.

Jackson, P.W. (1968). Life in classrooms. New York: Basic.

Nedyalkova, A., Z.Bauman, \& D.Filipov (2005). Globalism, regionalism and antiglobalism. Sofia: Albatros (in Bulgarian).

Portes, A. (1998). Social capital: Its origins and applications in modern sociology. Annual Review of Sociology, 24, 1-24.

Sherman, D. (1996). Creating the dropout: An institutional and social history of school failure. Westport: Greenwood Publishing Group. 